\title{
Aa. Vv., Yves Bonnefoy
}

Ida Merello

\section{(2) OpenEdition}

\section{Journals}

\section{Edizione digitale}

URL: https://journals.openedition.org/studifrancesi/38367

DOI: 10.4000/studifrancesi.38367

ISSN: 2427-5856

\section{Editore}

Rosenberg \& Sellier

\section{Edizione cartacea}

Data di pubblicazione: 15 décembre 2004

Paginazione: 652-653

ISSN: 0039-2944

\section{Notizia bibliografica digitale}

Ida Merello, «Aa. Vv., Yves Bonnefoy», Studi Francesi [Online], 144 (XLVIII | III) | 2004, online dal 30

novembre 2015, consultato il 08 mai 2021. URL: http://journals.openedition.org/studifrancesi/38367 ; DOI: https://doi.org/10.4000/studifrancesi.38367

\section{Questo documento è stato generato automaticamente il 8 mai 2021.}

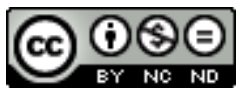

Studi Francesi è distribuita con Licenza Creative Commons Attribuzione - Non commerciale - Non opere derivate 4.0 Internazionale. 


\title{
Aa. Vv., Yves Bonnefoy
}

\author{
Ida Merello
}

\section{NOTIZIA}

YVES BONNEFOY, «Europe» n 890-891, juin-juillet 2003.

1 Questo numero monografico raccoglie testimonianze di amici e discepoli dello scrittore, oltre che una lunga intervista a cura di Fabio sсотто. È pressoché impossibile render conto di tutti gli interventi, che affrontano l'opera bonnefoyana da molteplici punti di vista, pur se spesso nel corso di poche pagine. Indichiamo qui di seguito gli interventi di maggiore ampiezza. Claude ESTEBAN ricorda le confidenze del poeta relative all'influenza esercitata sul suo immaginario dal paesaggio scabro e spoglio della regione al confine tra Rouergue e Quercy in cui passava le vacanze; Joseph FRANCK indaga sulle influenze russe in Bonnefoy, da Dostoievski a Chestov, conosciuto nella traduzione dell'amico Boris de Schloezer, per poi ricordare anche gli influssi della letteratura inglese, soffermandosi su Wordsworth. Patrick NÉE, studiando le influenze filosofiche dopo il periodo surrealista, cerca di far emergere un'ampia stratificazione di letture, da Chestov, Kierkegaard a John Wahl, mostrando come sia attraverso Wahl che vengono letti Hegel e Kierkegaard, mentre Wahl è letto a sua volta da Etienne Gilson. Anche Isabelle de monTmoLuin legge le influenze filosofiche sull'opera di Bonnefoy, da Chestov a Husserl, insistendo sull'aspirazione alla ricerca dell'unicità dell'essere da parte di Bonnefoy; mentre Jacqueline RISSET da un lato ricorda le letture di Virgilio e di Hölderlin, dall'altro della tradizione classica francese, come Racine, senza dimenticare i libri per ragazzi letti nell'infanzia, dimostrando il profondo legame tra lettura, infanzia e sogno: per questo in Récits en rêve e in La Vie errante l'A. scorge molti libri letti, o sogni di libri. Fabio sсотто si occupa proprio dei Récits en rêve, forma d'espressione o genere letterario che risulta essenziale per il poeta a partire da Rue traversière. (anche se l'A. ricorda come già al di sotto di Douve fosse presente un testo in prosa, poi abbandonato) ed è fondato su di un'analogia tra la scrittura poetica e la rottura dei legami di causalità nel processo onirico. scotTo sottolinea anche, all'interno di questo processo, la 
centralità dell'influenza della pittura, fino allo stabilirsi di un'analogia tra il carattere non verbale del segno pittorico e la dimensione gestuale della scrittura. François LALLIER ritorna sui Récits en rêve, sottolineando la differenza tra récit de rêve o en rêve e indicandoli come il tentativo di superare il discrimine tra poesia, racconto e critica. Michael EDWARDS sceglie, all'interno della riflessione bonnefoyana sui rapporti tra pittura e poesia, di soffermarsi sulle poesie che hanno per oggetto un quadro e in particolare su Dedham, vu de Langham, cui sono sottesi diversi quadri di Constable. L'A. mostra come Bonnefoy voglia, col suo testo, inserire nella rappresentazione gli elementi fonici, trattenendo della pittura solo la luce, introducendo in modo del tutto surrettizio la morte. John NAUGHTON crede di scorgere, nell'ultima produzione di Bonnefoy una sempre maggiore tendenza autobiografica; Dominique comBE sottolinea il legame dell'opera di Bonnefoy con la tradizione umanista, legame che si coglie nei continui riferimenti e citazioni non accademici ad esempio a Virgilio, Ovidio, Lucrezio. John E.JACKSON scandaglia invece il rapporto tra Bonnefoy e Shakespeare, analizzando le scelte traduttive del nostro; Marie-Claire BANCQUART approfondisce la questione del rapporto con Rimbaud, soffermandosi sul capitolo IX del Rimbaud scritto da Bonnefoy per Hachette nel 1968 e quindi sull'intervista del 1981 su Poésie et analogie e del 1983 Sur la difficulté de la communication poétique; Michèle FINK verifica l'ipotesi che la prima sezione di Hier régnant désert possa leggersi come un dialogo con Eliot, ipotesi già parzialmente confermata dall'articolo su Eliot che Bonnefoy pubblicò nel 1959; Marlène ZARADER stabilisce invece un parallelo con Louis-René des Forêts. 